\title{
Flexure-Compression Testing of Bridge Timber Piles Retrofitted with Fiber Reinforced Polymers
}

\author{
Pablo Caiza, Moochul Shin, Bassem Andrawes \\ Department of Civil and Environmental Engineering, University of Illinois at Urbana-Champaign, Urbana, USA \\ Email: pcaizas2@illinois.edu,mshin7@illinois.edu, andrawes@illinois.edu
}

Received July 18, 2012; revised August 20, 2012; accepted September 4, 2012

\begin{abstract}
The adequacy of using Fiber Reinforced Polymer (FRP) retrofit technique to restore the flexure-compression behavior of deteriorated bridge timber piles is examined experimentally in this paper. Sixteen specimens are tested monotonically under eccentric compressive loading. The specimens are first tested in their unretrofitted condition to determine their elastic properties. Each specimen is then cut and connected (posted) using the proposed FRP retrofit technique, and retested. The results show that the retrofitted specimens are capable of reaching same or higher strengths than that of the unretrofitted specimens with minimal reduction in their stiffness. Based on the experimental results, a design equation is presented to compute the volumetric ratio of FRP needed for retrofitting bridge timber piles under eccentric load.
\end{abstract}

Keywords: Bridges; Timber Piles; Eccentric Loading; Fiber-Reinforced Polymer (FRP)

\section{Introduction}

The relatively limited maintenance and attention which small rural bridges often receive throughout their service life could potentially result in the rapid deterioration of these bridges' structural conditions. Due to this fact along with the consistent increase in population and loading demands, many of these bridges reach a point where they fail to accommodate current traffic volumes, vehicle sizes, and weights [1-3]. Taking into account the high cost of replacing those bridges, every effort is needed to develop sound and cost-effective retrofit measures that can effectively extend the service life of these bridges.

Among the bridges that are commonly found in rural areas are the ones that are supported on timber piles. Bridges supported on timber piles are vulnerable to extreme loadings as well as harsh environmental conditions which could lead to rapid decay of the wood if the piles are not regularly monitored [4]. In the United States and other parts of the world, some measures are often taken to delay or prevent the decay of bridge timber piles, such as the use of creosote oil and the regular inspection of the piles. If inspection reveals that a portion of the pile is in a bad condition and in need for replacement, a technique often known as "posting" is utilized. Posting a pile is a process where a portion of the pile is cut out and replaced with a new piece of timber, see Figure 1. This new piece is connected to the existing pile by embedded metal fasteners [5]. The post connection at the interface between the existing timber and the new timber is capable of transmitting axial compression forces only; however it is not designed to transfer moment. Nonetheless, due to its cost-effectiveness this type of retrofit technique is preferred to a complete replacement of the entire pile or encasing of the timber pile in a thick reinforced concrete shell.

Although the pile posting retrofit technique is commonly used, its limited ability to restore the flexural capacity of the piles is considered to be a major drawback that could potentially cause severe consequences as in the case of a relatively recent bridge collapse incident in the State of Illinois [6,7]. Investigation suggested that the collapse of this bridge was due to the presence of flexural bending in addition to axial compression applied to the posted timber piles. Hence, there is a dire need for a simple and reliable procedure that could enhance the flexurecompression behavior of posted piles at the post connection interfaces. One of the relatively recent approaches studied to restore the load-carrying capacity of heavily

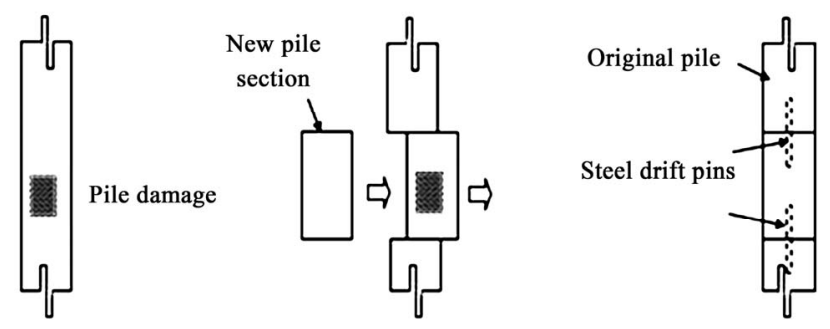

Figure 1. Replacement of a wood piece from a damaged timber pile. 
decayed timber piles is the use of fiber reinforced polymer (FRP) wraps on the top of a relatively thin cementitious grout shell around the timber pile. In most of the research done in this area, glass-FRP (GFRP) wraps are basically used to confine the grout shell and the timber core, in such a way that only the axial compression capacity of the piles is improved [8]. However, no studies, to the knowledge of the authors, have been conducted specifically to investigate the combined flexure-compression behavior of timber pile post connections retrofitted with FRPs. This paper aims at studying the feasibility of using FRP wraps as a mean for splicing the new post with the existing pile in a way that ensures the flexural integrity of the retrofitted pile. The paper discusses an experimental program which was carried out on retrofitted timber piles tested under uniaxial concentric and eccentric loading. The paper starts by discussing the proposed retrofit technique in Section 2 followed by a description presented in Sections 3 and 4 for the timber pile specimens used in the tests and the test setup adopted in this study, respectively. A detailed discussion is then presented in Section 5 on the approach used in designing the FRP wraps used in the tests followed by a discussion in Section 6 on the test results. Finally, the test results are used in Section 7 to develop design recommendations for FRP-retrofitted timber piles subjected to eccentric loading.

\section{Proposed Retrofit Technique}

Figure 2 shows schematics of the proposed retrofit tech-

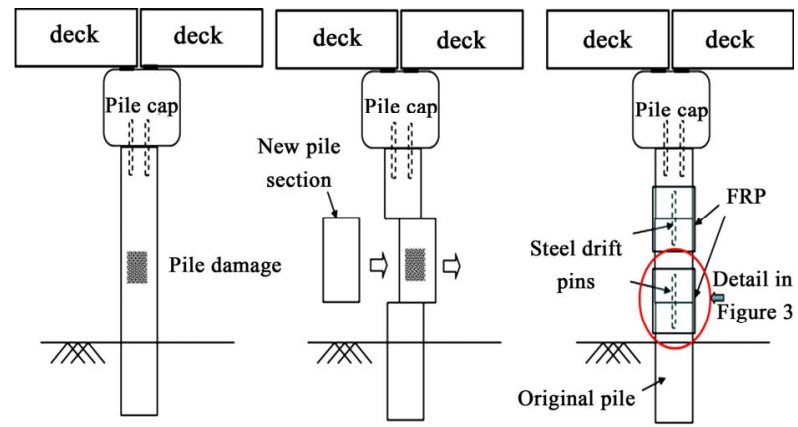

Figure 2. Proposed retrofit technique.

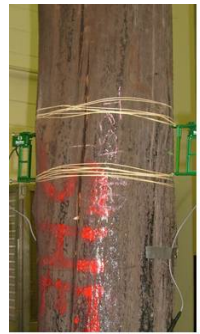

(a)

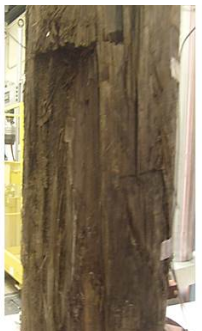

(b)

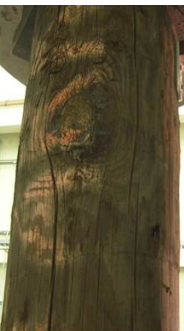

(c) nique which was adopted in this study. The first step is to align the timber post and the existing pile and connect them using a vertical steel drift pin at the center of the round pile (Figure $3(\mathbf{a})$ ) or by using nails driven at the sides of the pile (Figure 3(b)). After the two spliced pieces of timber are attached, the round surface of the timber pile is sanded, and a thin mortar shell (less than 2 $\mathrm{mm}$ ) could be applied to provide an evenly round surface for the FRP sheets which will be wrapped in the next step. Another advantage of using the mortar shell is to block the creosote oil that could possibly be within the wood from contaminating the FRP resin. Finally, the FRP sheets are applied around the pile with resin using the hand lay-up process.

\section{Specimen Description}

The experimental specimens used in this study were cut from pile samples that were retrieved from several bridges in the state of Illinois. The retrieved samples were different in their dimensions (length and diameter) and their age, which directly affected the level of deterioration in each specimen. It should be noted, however, that all timber piles sustained relatively moderate levels of decay. Figure 4 shows different types of decay which was observed in the tested specimens including vertical cracks (Figure 4(a)), partially crushed fibers (Figure 4(b)), irregular shape of the section due to the existence of a knot (Figure 4(c)), and cracks filled with mold and fungus (Figure 4(d)).

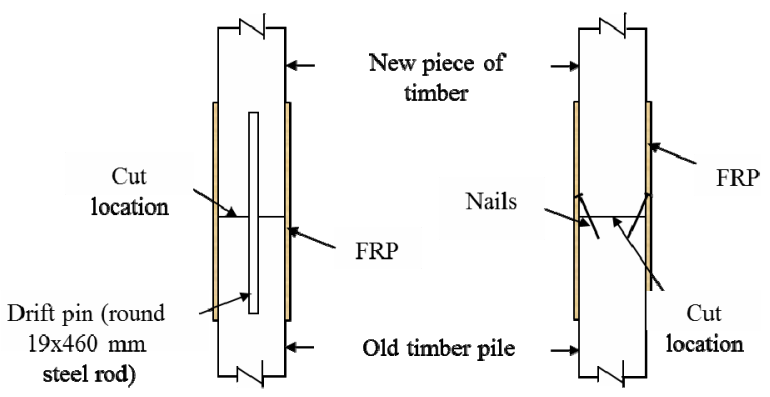

(a)

(b)

Figure 3. Detail of a post connection of a timber-pile.

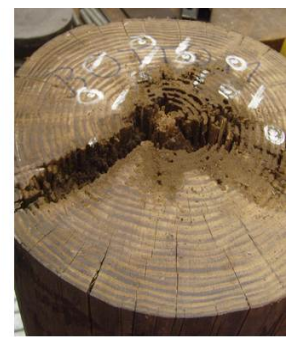

(d)

Figure 4. Different types of decay observed in the tested pile specimens: (a) Vertical crack; (b) Partially crushed fibers; (c) Irregular shape; (d) Mold and fungus inside of cracks. 
In total, 16 specimens were prepared by cutting them from the retrieved piles. The specimens were cut to a constant length of $1220 \mathrm{~mm}$, and their diameter varied between $249 \mathrm{~mm}$ and $318 \mathrm{~mm}$. Each specimen was tested twice under combined flexure-compression loading. The purpose of the first test was to determine the strength and stiffness of the unretrofitted timber piles. Next, the specimen was cut perpendicular to its longitudinal axis in two equal halves, and the two halves were spliced together using the proposed retrofit technique, i.e. with a steel drift pin or nails and FRP sheets. The second flexure-compression test was carried out next, to examine the behavior of the spliced specimens after being retrofitted with FRP wraps. The specimen test matrix is summarized in Table 1. The nomenclatures used herein for the unretrofitted and retrofitted specimens are SPxU and SPxR, respectively, where " $x$ " indicated the specimen number. Two of the 16 specimens were retrofitted with carbon FRP (CFRP) sheets (SP9 and SP13), while the rest of the specimens were wrapped with GFRP sheets.

In order to examine the effect of using mortar shell prior to wrapping the FRP sheets, a mortar shell was utilized in the retrofit of specimens SP8, SP9, SP10, and SP11. To explore the effect of the presence of excessive decay and cavities in the piles, a wedge was introduced in two of the tested specimens (SP12 and SP13) as shown in Figure 5. As shown in the figure, the wedge was introduced by cutting out a portion of the pile and filling it with mortar prior to FRP wrapping. Furthermore, since the use of center-lined drift pins to align the two spliced timber pieces could be problematic in the field, the possibility of using diagonally driven nails at

Table 1. Specimens test matrix.

\begin{tabular}{ccc}
\hline Specimen & D [mm] & Retrofit Details \\
\hline SP1 & 262 & GFRP \\
SP2 & 290 & GFRP \\
SP3 & 249 & GFRP \\
SP4 & 282 & GFRP \\
SP5 & 262 & GFRP \\
SP6 & 277 & GFRP \\
SP7 & 254 & GFRP \\
SP8 & 318 & GFRP, mortar shell \\
SP9 & 305 & CFRP, mortar shell \\
SP10 & 315 & GFRP, mortar shell \\
SP11 & 310 & GFRP, mortar shell \\
SP12 & 318 & GFRP, wedge \\
SP13 & 292 & CFRP, wedge \\
SP14 & 259 & GFRP, nails \\
SP15 & 290 & GFRP, nails \\
SP16 & 318 & GFRP, nails \\
\hline
\end{tabular}

the sides of the specimen was examined in three specimens (SP14, SP15, and SP16). Figure 6 presents pictures illustrating the procedures used in preparing the tested specimens.

Table 2 summarizes properties and details of the materials used in retrofitting the specimens. Vinylester resin was used to form the matrix of both GFRP and CFRP. The glass fabric used was woven roving, and was selected for its relatively inexpensive, high impact, and high strength two-directional reinforcement properties. The carbon fabric used was plain weave, which is characterized with light-weight and high stiffness. The concrete mortar has a relatively high compressive strength of $22 \mathrm{MPa}$ at 1 day, as well as a fast final set time of 2 hours. It comprises one component, microfiber, silica plus polymer mortar.

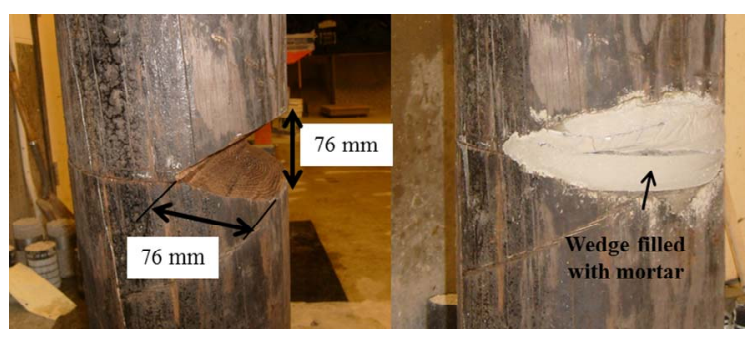

Figure 5. Wedge at the post connection.

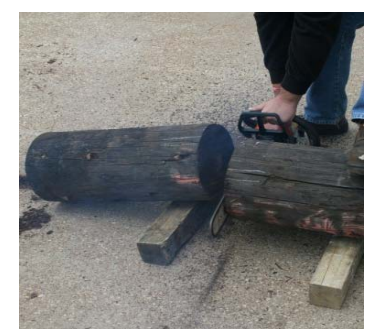

(a) Pile cutting

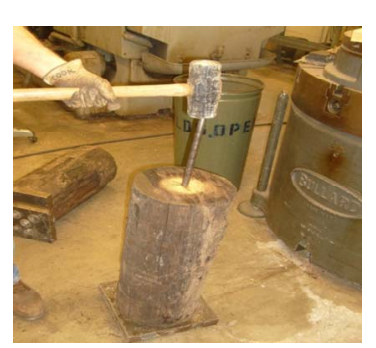

(b) Steel pin installation

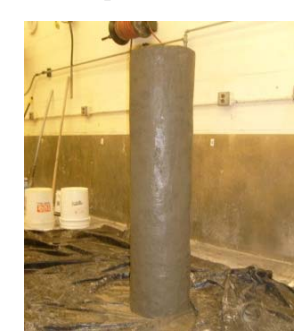

(d) Mortar shell (c) Sanding

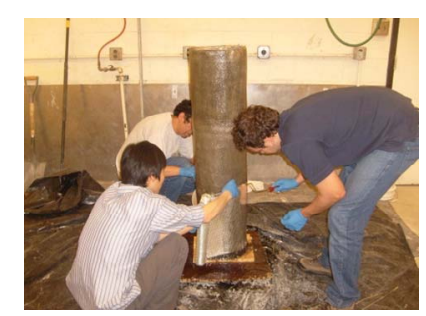

(e) FRP wrapping

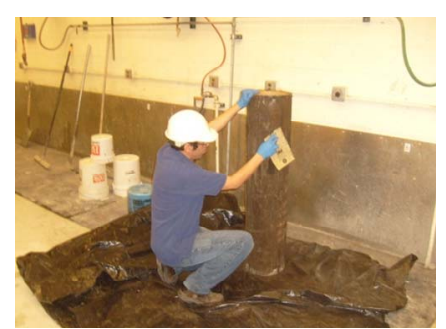

(c) FRP wrapping
Figure 6. Details of the pile retrofit procedure. 
Table 2. Properties of the materials used to retrofit the timber piles.

\begin{tabular}{cl}
\hline Material & \multicolumn{1}{c}{ Properties } \\
\hline Glass FRP & $\begin{array}{l}\text { Modulus of elasticity }=12,400 \mathrm{MPa}, \\
\text { thickness }=0.6 \mathrm{~mm}\end{array}$ \\
Carbon FRP & $\begin{array}{l}\text { Modulus of elasticity }=135,800 \mathrm{MPa}, \\
\text { thickness }=0.3 \mathrm{~mm}\end{array}$ \\
Concrete mortar & $\begin{array}{l}\text { Compressive strength }(1 \text { day })=22 \mathrm{MPa}, \\
\text { final set time of 2 hours. }\end{array}$ \\
\hline
\end{tabular}

\section{Test Set-Up}

The tests performed in this study were conducted using a $2670 \mathrm{kN}$ MTS uniaxial servo-controlled compression machine. The actuator was controlled by an INSTRON 8800 controller. The testing frame contained an internal load cell and an internal Linear Variable Differential Transducer (LVDT) to measure actuator position. The specimens were instrumented with two vertical extensometers placed at the mid-height of the specimen on two opposite sides to measure axial strains (see Figure 7).

Two additional LVDTs were placed at the top and bottom of the pile specimen to monitor the relative displacement between the specimen and the end plates during testing. The typical disposition of the LVDT located at the top of the pile is also shown in Figure 8.

Special fixture plates were designed, manufactured, and mounted at both ends of the specimen to apply the axial load eccentrically. The specimens were bolted to 38 $\mathrm{mm}$ thick steel plates on each end using ten $19 \times 151 \mathrm{~mm}$ bolts for the top plate and eight $19 \times 151 \mathrm{~mm}$ bolts for the bottom plate. Figure 9 shows schematics of the special plates used for applying the eccentric load.

The plates were loaded through $51 \mathrm{~mm}$ diameter rollers which were placed at distance of $76 \mathrm{~mm}$ from the centroidal axis of the pile specimen (see Figure 10). Figure 11 shows an installed specimen in the $2670 \mathrm{kN}$ machine frame. As indicated by the described test setup,

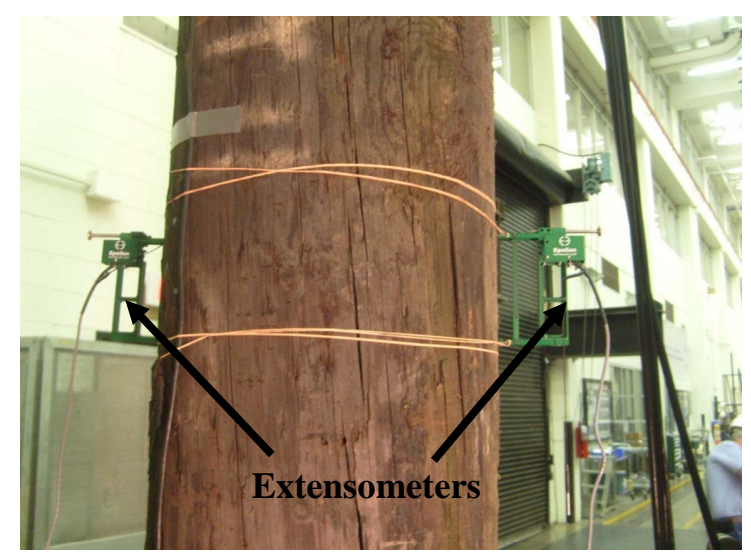

Figure 7. Longitudinal extensometers on both sides of the specimen.

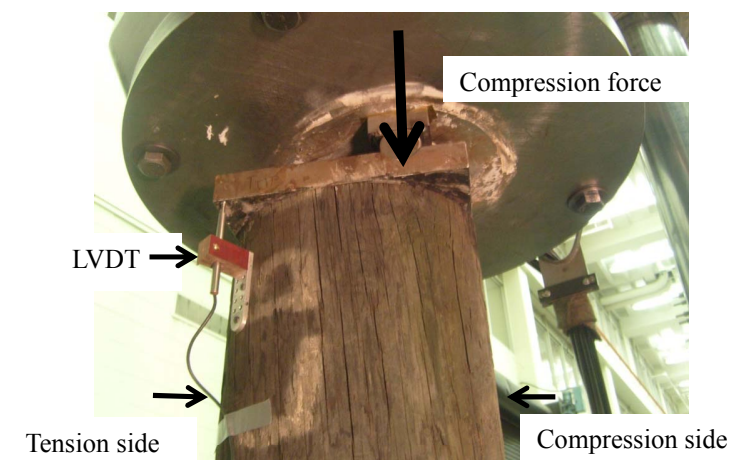

Figure 8. Installed LVDT at the top of the pile.
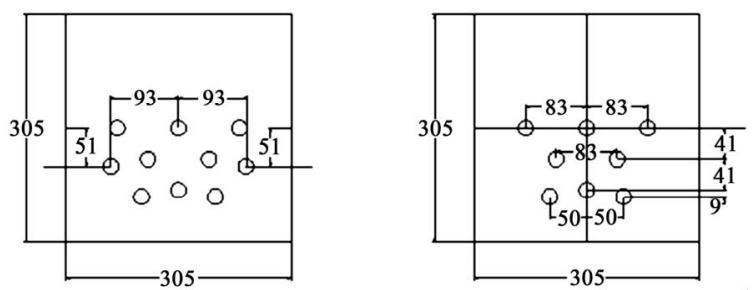

Figure 9. Steel fixture plates used to apply eccentric axial load on the specimens (Dimensions in $\mathbf{m m}$ ).

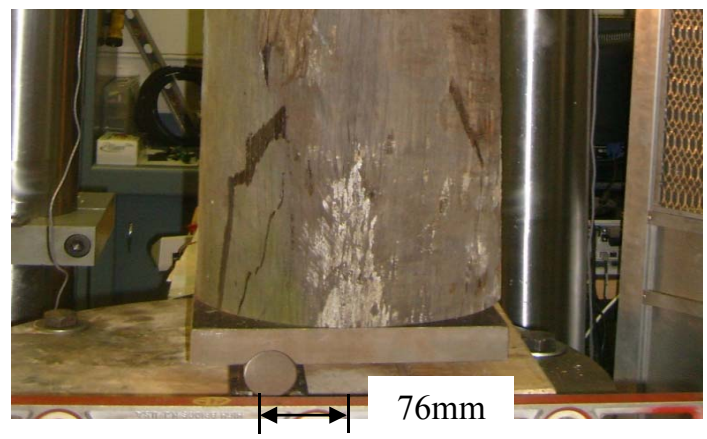

Figure 10. Typical roller at the base of the pile.

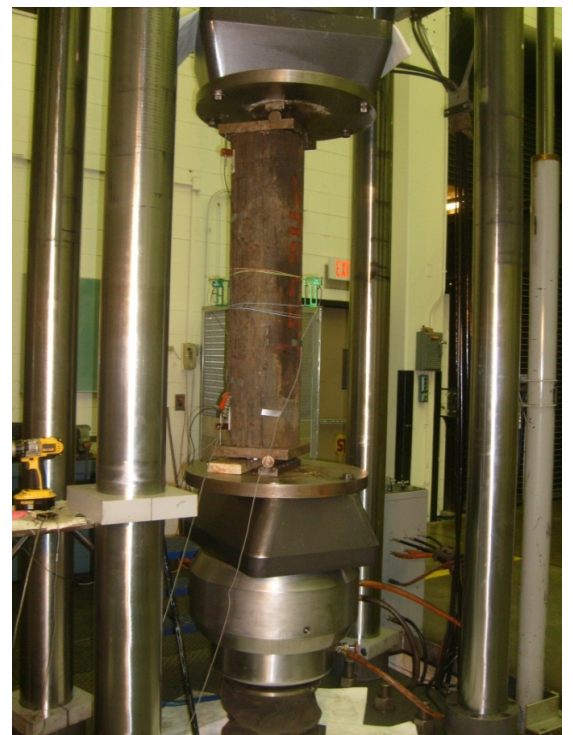

Figure 11. Installed specimen in the MTS testing machine. 
a monotonic compression load with an eccentricity of 76 $\mathrm{mm}$ was applied to the timber-pile specimens. The tests were conducted under displacement control at $1.27 \mathrm{~mm}$ per minute cross-head rate. First, an unretrofitted specimen was tested until a point where nonlinear behavior of the specimen was observed. The maximum load recorded at this point was considered as the elastic strength of the pile specimen. Then, the specimen was cut to simulate a post connection, and retrofitted with a proper number of FRP wraps satisfying the elastic design criteria of the FRP retrofit, which is discussed in the following section. The retrofitted specimen is then reloaded until the first sign of nonlinearity in the force-deformation relationship is observed.

\section{Elastic Design of FRP Wraps}

In order to determine the number of FRP layers needed for the retrofitting of the piles, an elastic design procedure was adopted. The procedure was based on the assumption that at the interface section between the post and the old pile, the tensile stresses are resisted entirely by the FRP, and the compressive stresses are resisted by both wood and FRP. At this section, the portion of the wood resisting compression is called "effective area" (see Figure 12).

To determine the number of FRP layers that gives the same flexural stiffness in the retrofitted pile as that of the unretrofitted pile, the following formula was used:

$$
E_{\text {Wood }} I=E_{\text {Wood }} I_{\text {comp }}+E_{\text {FRP }} I_{\text {FRP }}
$$

where $E_{\text {wood }}$ is the modulus of elasticity of wood, $I$ is moment of inertia of the complete circular section of the original pile, $I_{\text {comp }}$ is the moment of inertia of the effective area of the pile section (Figure 12), $E_{F R P}$ is the modulus of elasticity of FRP, and $I_{F R P}$ is the moment of inertia of the FRP wraps used for the retrofitting of timber pile.

Equation (1) was used to derive the formula used to compute the required $F R P$ volumetric ratio, $\rho_{F R P}$, which is defined as the ratio between the volumes of FRP and timber. The volumetric ratio of FRP can be expressed as $\frac{(D+2 n t)^{2}-D^{2}}{D^{2}}$, where $D$ is the diameter of the pile, $n$

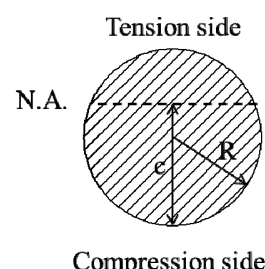

(a) Original section

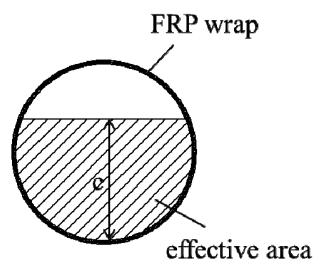

(b) Retrofitted section
Figure 12. Original vs. retrofitted section at the post connection interface. is the number of FRP layers, $t$ is the thickness of a single FRP layer. Using Equation (1), the volumetric ratio of $F R P$ can be described as:

$$
\rho_{F R P}=-1+\sqrt{1+\left(1-\frac{I_{\text {comp }}}{I}\right) \frac{E_{\text {Wood }}}{E_{F R P}}}
$$

Additionally, Equation (2) can be rewritten in terms of the required number of FRP layers as follows:

$$
n=\frac{D}{2 t}\left(\left(1+\left(1-\frac{I_{\text {comp }}}{I}\right) \frac{E_{\text {wood }}}{E_{F R P}}\right)^{\frac{1}{4}}-1\right)
$$

The moment of inertia of the effective area of the timber pile section is calculated from the following equation:

$$
\begin{aligned}
I_{\text {comp }}= & \pi \frac{R^{4}}{8}+\frac{y_{1}^{*}}{2} \sqrt{\left(R^{2}-y_{1}^{* 2}\right)^{3}} \\
- & \frac{R^{2}}{4}\left[y_{1}^{*} \sqrt{R^{2}-y_{1}^{* 2}}+R^{2} \sin ^{-1}\left(\frac{y_{1}^{*}}{R}\right)\right] ; \\
R=\frac{D}{2} & y_{1}^{*}=R-c
\end{aligned}
$$

where $c$ is the depth of the effective area of the timberpile section (Figure 12). Note that c can be calculated from the classical equation for elastic stresses $[10,11]$ :

$$
c=\frac{D}{2}+\frac{I}{A e}
$$

where, $A$ is area of the circular section of the pile, and $e$ is eccentricity.

Figure 13 shows an example of the strain distribution at the interface/mid-height determined from the tests using the two extensometers attached on both sides of the specimen. In this figure, compressive strains are considered negative and tensile strains positive. The presented distributions are for the unretrofitted (SP4U) and retrofitted (SP4R) specimen 4. Using the experimental strain data, the depth of the effective area was found to be 201 $\mathrm{mm}$ and $218 \mathrm{~mm}$ for SP4R and SP4U, respectively with a difference of $7.8 \%$. For comparison, the analytical depth of the effective area was also computed using Equation

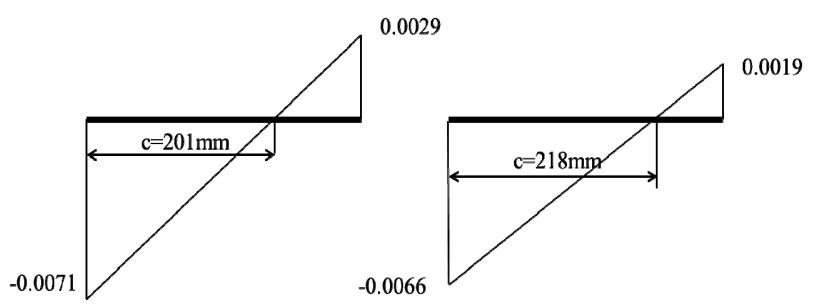

(a) SP4R

(b) SP4U

Figure 13. Strain distribution at mid-height of specimen SP4 $(D=282 \mathrm{~mm})$. 
(5) and was found to be $206 \mathrm{~mm}$; hence the differences between the analytical and experimental $c$ values of the retrofitted and unretrofitted specimens were approximately $2.5 \%$ and $5.8 \%$, respectively. This minor difference could possibly be due to imperfections in the piles' circular section and decay and damage of the wood.

As stated earlier, the diameter of the section of the timber piles (D) varied between 249 and $318 \mathrm{~mm}$, correspondingly $\frac{I_{\text {comp }}}{I}$ varied between 0.55 and 0.61 . If the mean value for $\frac{I_{\text {comp }}}{I}$ (i.e. 0.58) is used, Equation (2) can be further simplified to

$$
\rho_{F R P}=-1+\sqrt{1+0.42 \frac{E_{\text {Wood }}}{E_{F R P}}}
$$

Equation (6) shows that the ratio $\frac{E_{\text {wood }}}{E_{F R P}}$ is the key factor governing the design of FRP, but the modulus of elasticity of wood and FRP can vary substantially [12]. As shown in Table 2, the modulus of elasticity of GFRP and CFRP used in this study was $12,400 \mathrm{MPa}$ and $135,800 \mathrm{MPa}$, respectively. The modulus of elasticity of the wood on the other hand was determined experimentally using the results of the tests conducted on unretrofitted specimens. Based on the results of the 16 tested specimens, the mean value of the modulus of elasticity of wood was found to be $4474 \mathrm{MPa}$ with standard deviation of $1234 \mathrm{MPa}$. In addition, there is a $95 \%$ confidence that the value of the modulus of elasticity is between 3820 $\mathrm{MPa}$ and $5136 \mathrm{MPa}$. It is worth noting that the National Design Specification for Wood Construction [13] recommends the following values for modulus of elasticity of treated round timber piles for normal load duration and wet service conditions of Northern and Southern Red Oak: $E=8618 \mathrm{MPa}$ and $E_{\min }=4550 \mathrm{MPa}$. To be on the conservative side, the value of $E_{\min }$ was chosen as the modulus of elasticity for timber in the pile retrofit tests since it is quite close to the mean value and within $95 \%$ confidence interval of the experimental values.

Based on the described design procedure, the number of FRP layers used for each specimen was calculated and is summarized in Table 3 . The second row in the table corresponds to the number of FRP layers predicted using Equation (3), while the third row corresponds to the number of layers actually used in the tests. The fourth row shows the FRP volumetric ratio $\left(\rho_{F R P}\right)$. As shown in the table, a number of layers similar to or greater than the predicted number from Equation (3) was utilized for retrofitting specimen SP1 and specimens SP8 through SP13. However, since most of these tests showed that the retrofitted specimens reach higher strength than that of the unretrofitted specimens, and in order to optimize the design of the FRP sheets, using smaller number of layers than those computed based on Equation (3) was also considered. It is important to point out that the CFRP volumetric ratios used for SP9 and SP13 are much smaller than those of the GFRP retrofitted specimens due to the significantly higher modulus of elasticity of CFRP compared to GFRP.

\section{Experimental Results}

The results of the flexure-compression tests of all 16 pile specimens are summarized in Table 4 . The table is divided into four sections depending on the retrofit details used for the specimens. The specimens were retrofitted: 1) with FRP sheets without mortar shell, 2) with FRP sheets and mortar shell, 3) with FRP sheets and mortar-filled wedges, and 4) with only FRP sheets but the pile was connected using nails while other specimens under the previous sections were connected using steel drift pins (see Figure 3). The second and third rows in each section of the table represent the maximum compression forces of the unretrofitted $\left(P_{\text {unret }}\right)$ and retrofitted $\left(P_{r e t}\right)$ specimens, respectively. The fourth row presents the ratio between retrofitted and unretrofitted maximum forces. It

Table 3. Number of FRP layers and volumetric ratios.

\begin{tabular}{|c|c|c|c|c|c|c|c|c|c|}
\hline & & SP1R & SP8R & SP9R & SP10R & SP11R & SP12R & SP13R & SP2R \\
\hline \multirow[t]{2}{*}{ No. of FRP layers } & Equation (3) & 8 & 9 & 2 & 9 & 9 & 9 & 2 & 9 \\
\hline & Test & 8 & 9 & 2 & 10 & 9 & 9 & 2 & 7 \\
\hline \multirow[t]{2}{*}{$\rho_{F R P}$} & Test & 0.079 & 0.074 & 0.008 & 0.084 & 0.076 & 0.073 & 0.008 & 0.062 \\
\hline & & SP3R & SP4R & SP5R & SP6R & SP7R & SP14R & SP15R & SP16R \\
\hline \multirow[t]{2}{*}{ No. of FRP layers } & Equation (3) & 8 & 9 & 8 & 8 & 8 & 8 & 9 & 9 \\
\hline & Test & 6 & 7 & 6 & 6 & 6 & 6 & 6 & 7 \\
\hline$\rho_{F R P}$ & Test & 0.062 & 0.064 & 0.059 & 0.056 & 0.061 & 0.060 & 0.053 & 0.057 \\
\hline
\end{tabular}


Table 4. Maximum forces of unretrofitted and retrofitted specimens under flexure-compression tests.

\begin{tabular}{|c|c|c|c|c|c|c|c|}
\hline \multicolumn{8}{|c|}{ Without mortar shell } \\
\hline Specimen & SP1 & SP2 & SP3 & SP4 & SP5 & SP6 & SP7 \\
\hline$P_{\text {unret }}[\mathrm{kN}]$ & 347 & 436 & 289 & 863 & 516 & 565 & 325 \\
\hline$P_{r e t}[\mathrm{kN}]$ & 387 & 529 & 329 & 912 & 467 & 565 & 3253 \\
\hline$P_{\text {ret }} / P_{\text {unret }}$ & 1.12 & 1.21 & 1.14 & 1.06 & 0.91 & 1.00 & 1.00 \\
\hline \multicolumn{8}{|c|}{ With mortar shell } \\
\hline Specimen & SP8 & SP9 & SP10 & SP11 & & & \\
\hline$P_{\text {unret }}[\mathrm{kN}]$ & 1406 & 787 & 555 & 681 & & & \\
\hline$P_{r e t}[\mathrm{kN}]$ & 1397 & 778 & 681 & 810 & & & \\
\hline$P_{\text {ret }} / P_{\text {unret }}$ & 0.99 & 0.99 & 1.23 & 1.19 & & & \\
\hline \multicolumn{8}{|c|}{ With wedge } \\
\hline Specimen & SP12 & SP13 & & & & & \\
\hline$P_{\text {unret }}[\mathrm{kN}]$ & 592 & 725 & & & & & \\
\hline$P_{r e t}[\mathrm{kN}]$ & 801 & 360 & & & & & \\
\hline$P_{\text {ret }} / P_{\text {unret }}$ & 1.35 & 0.50 & & & & & \\
\hline \multicolumn{8}{|c|}{ With Nails } \\
\hline Specimen & SP14 & SP15 & SP16 & & & & \\
\hline$P_{\text {unret }}[\mathrm{kN}]$ & 302 & 498 & 632 & & & & \\
\hline$P_{r e t}[\mathrm{kN}]$ & 351 & 498 & 623 & & & & \\
\hline$P_{\text {ret }} / P_{\text {unret }}$ & 1.16 & 1.00 & 0.99 & & & & \\
\hline
\end{tabular}

is important to highlight cases such as SP8 and SP16 with the same size and yet different strengths due to different level of deterioration and defects in the wood.

The maximum forces attained in the retrofitted tests were similar to or greater than those obtained from the unretrofitted specimens regardless of the retrofitting details, with the exceptions of specimen SP5 and SP13. The strength of the retrofitted specimen SP5 was found to be $91 \%$ of that of the unretrofitted specimen. This slight reduction in strength could possibly be due to imperfectly wrapped FRP sheets since the surface of the specimen was quite uneven. Note that the specimens with mortar shell, which made the surface of the specimens more evenly round, showed no reduction in strength. For the case of SP13, due to the weak out of plane resistance of CFRP jacket, an early crushing of the filling material (mortar) in the wedge cut between the two halves of the timber pile specimen was observed. This weakness was produced by the extremely small thickness of the CFRP jacket. Further, the results shown in the table prove that using steel drift pins or nails results in similar performance, since the average $P_{r e t} / P_{\text {unret }}$ ratio for these cases 
were 1.06 and 1.05 , respectively.

To understand better how the behavior of retrofitted specimens compares to that of unretrofitted specimens, some selected force-displacement relationships for different retrofit details are presented in Figure 14. In this figure, the displacements are obtained from the internal LVDT of the compression machine, i.e. the displacements at the point of application of the compression load, $76 \mathrm{~mm}$ away from the centroid of the pile circular section. Early in the loading history, up to approximately $100 \mathrm{kN}$ both unretrofitted and retrofitted specimens had a softer behavior, in all cases, likely due to the flexibility of the loading frame. The retrofitted test was subsequently slightly softer than the unretrofitted test for cases (a) and (d) in Figure 14. This behavior is likely due to the slight damage that was exerted on the specimen when it was first tested while it was still unretrofitted. Moreover, it was found that the use of mortar shell together with FRP sheets (Figure 14(b)) helped in restoring the strength and stiffness of the pile. Hence, using mortar shell could be recommended in the cases of piles with higher levels of damage. In the case where a mortar-filled wedge is introduced prior to wrapping the specimen with FRP, since the elastic modulus of mortar was higher than the elastic

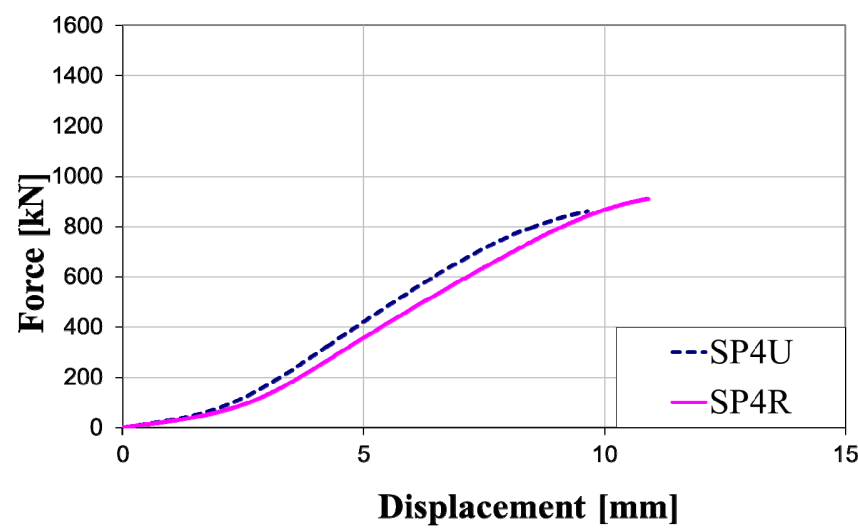

(a) Without mortar shell

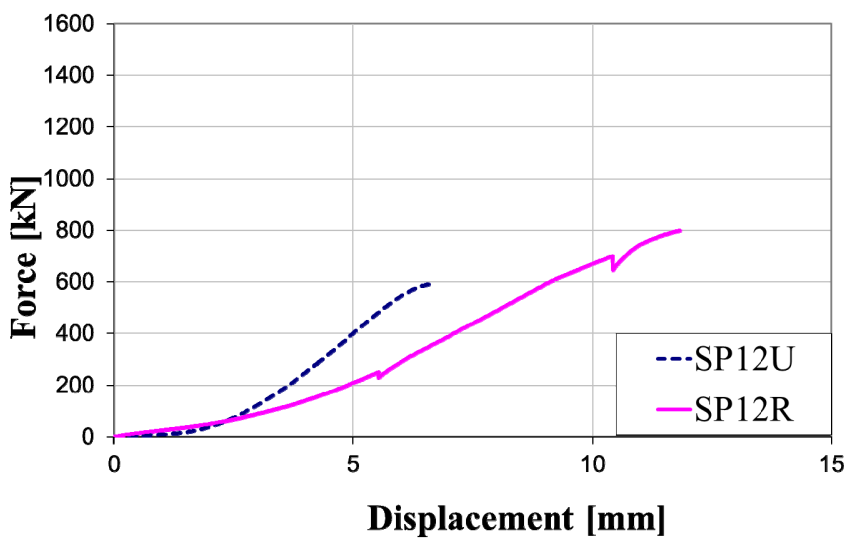

(c) With wedge modulus of the wood, the retrofitted pile showed higher stiffness than that of the unretrofitted pile at the initial stage (Figure 14(c)). However, as the testing progressed, the specimen became softer due to the weak out of plane resistance of CFRP jacket, as mentioned earlier, which provided very little confinement for the filling mortar resulting in its early crushing. From Figure 14(d), it is found that using nails or drift pins does not impact significantly the capacity or stiffness of the retrofitted piles.

In an elastic design of the pile cap and piles, forces are distributed from the pile cap to the piles according to the stiffness of each pile, since the pile cap can be regarded as a rigid body. Therefore, it was important to ensure that, although the strength of the retrofitted specimens was satisfactory, their stiffness is not significantly impacted. To eliminate the effect of early hardening which was highlighted earlier in the discussion, the stiffness was calculated after the specimen reaches a stable linear behavior. It was found by inspection that this behavior occurs approximately between one third and two thirds of the maximum force. Therefore, the stiffness results presented in this study were calculated using the middle portion of force-displacement curves.

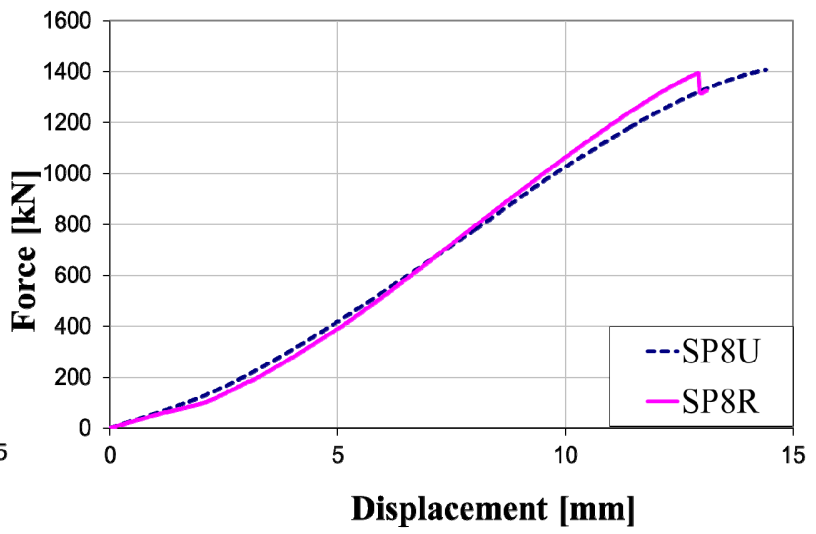

(b) With mortar shell

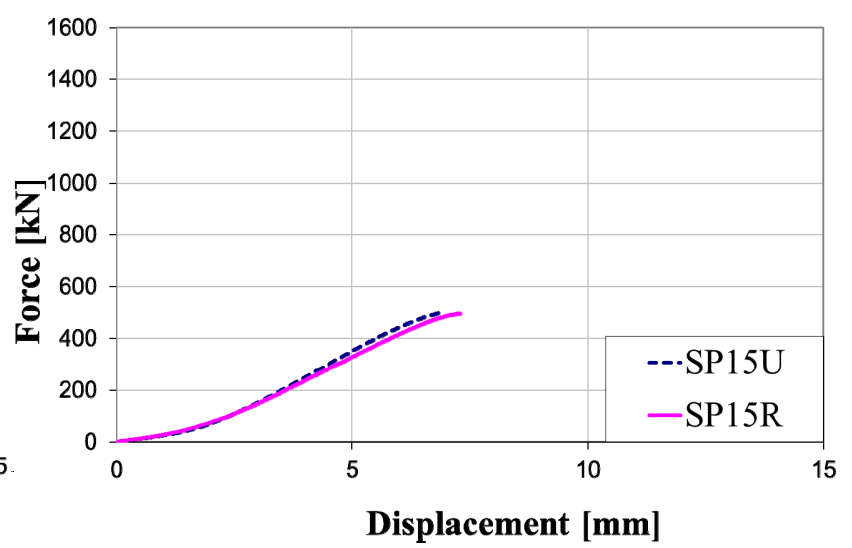

(d) With nails

Figure 14. Force-displacement relationship for specimens with different retrofit conditions. 
A comparison between the unretrofitted and retrofitted stiffness of each specimen is presented in Figure 15. The results of CFRP retrofitted specimens are excluded in Figure 15, since SP13 showed a different type of failure mechanism and also the results produced higher standard deviation when added to the GFRP test results; hence it was more conservative to eliminate them. SP11 was not presented either, since it experienced relatively extensive damage during the first (unretrofitted) test. The retrofitted specimens SP1, SP2 and SP8 show higher stiffness than that of the unretrofitted specimens since damage experienced in the specimens while conducting the unretrofitted test was extremely minor. By using mortar shell, the stiffness of the retrofitted specimens was fully restored, and the stiffness of specimens SP8R and SP10R was found to be $112 \%$ and $99 \%$ of the unretrofitted specimens, respectively. The stiffness results presented in Figure 15 showed a mean stiffness reduction of 5\% and median stiffness reduction of $14 \%$ for the retrofitted specimens compared with the unretrofitted specimens.

\section{Design Recommendation}

Figure 16 shows a graph of the ratios of the maximum retrofitted forces to the maximum unretrofitted forces with respect to the GFRP volumetric ratio used for the retrofitted specimens. A linear regression analysis was conducted and the result is shown as a solid straight line in the figure. The two dashed lines drawn in the figure represent $\mu \pm 2 \sigma$, where, $\mu$ is the mean and $\sigma$ is the standard deviation of the data points, respectively. As shown in the figure, only two data points lie below the lower dashed line; hence it was deemed appropriate to base the design on the $\mu-2 \sigma$ value. The design point is considered when the $\mu-2 \sigma$ line intersects the horizontal line corresponding to a $P_{r e t} / P_{\text {unret }}$ ratio equal to 1.0. Therefore, the design volumetric ratio of GFRP is found to be 0.068 . Note that only the tests with GFRP were used to calculate the results shown in Figure 16. It is important to note also that the average ratio of the retrofitted to the unretrofitted stiffnesses of the five specimens whose volumetric ratios is higher than the proposed value of 0.068 is 1.08 . This confirms that while similar strength can be expected by using the proposed volumetric ratio, the stiffness of the retrofitted specimens will not be jeopardized.

It is important to recall that the calculated volumetric ratio corresponds to the GFRP type used in this study. However, it can be generalized to accommodate other FRP types with different modulus of elasticity, $E_{F R P}$. The equivalent design FRP volumetric ratio $\left(\rho_{F R P-e q}\right)$ can be expressed as follows:

$$
\rho_{F R P-e q}=\rho_{F R P} \frac{12400}{E_{F R P}}
$$

where $\rho_{F R P}$ is the design volumetric ratio of FRP used in this study with $E_{F R P}$ equal to $12400 \mathrm{MPa}$. The number of layers $n$, corresponding to a layer thickness equal to $t$, needed to retrofit the timber pile post connection can be calculated as:

$$
n=\frac{D}{2 t}\left(\sqrt{1+\rho_{F R P-e q}}-1\right)
$$

Finally, Equations (8) and (9) can be merged to form the following equation:

$$
n=\frac{D}{2 t}\left(\sqrt{1+\rho_{F R P} \frac{12400}{E_{F R P}}}-1\right)
$$

As stated above, based on the experimental tests and after regression analysis, the optimal volumetric ratio $\rho_{F R P}$ is found to be 0.068 . Therefore, Equation (10) can be simplified to:

$$
n=\frac{D}{2 t}\left(\sqrt{1+\frac{843}{E_{F R P}}}-1\right)
$$

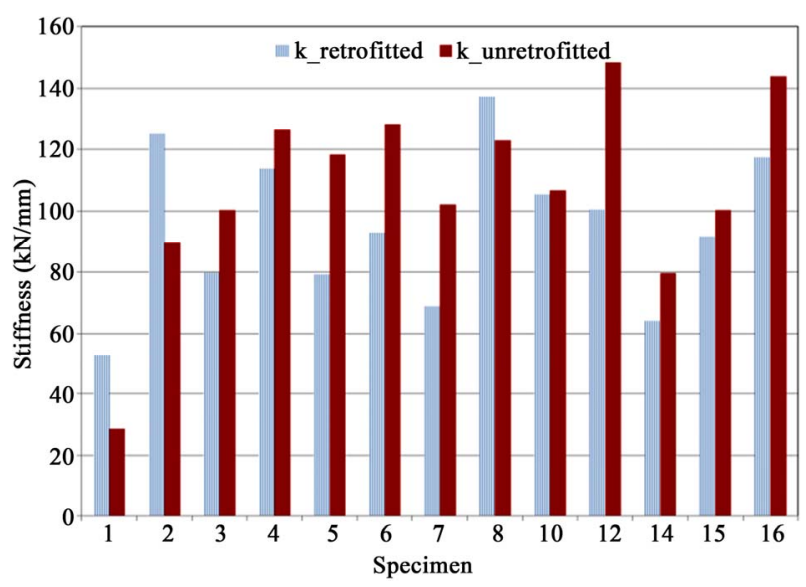

Figure 15. Stiffness of unretrofitted and retrofitted specimens.

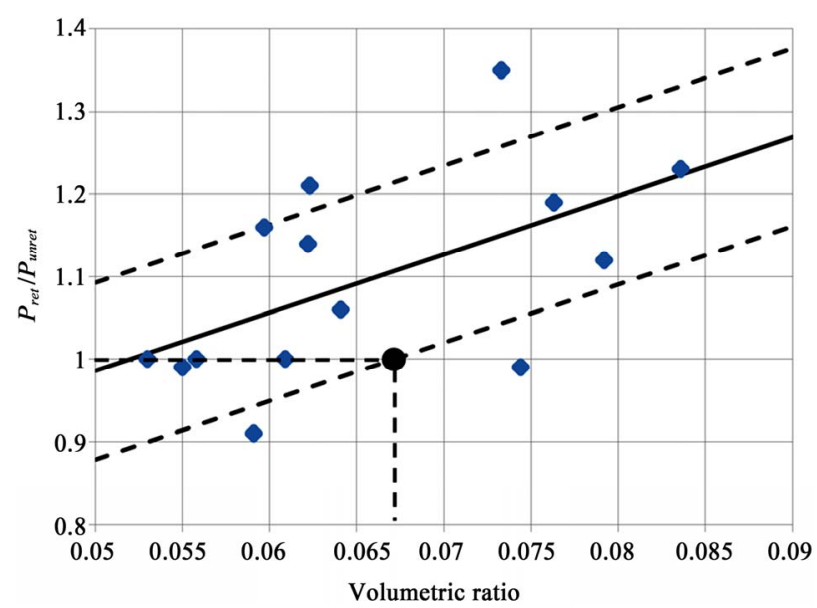

Figure 16. Regression analysis of the FRP volumetric ratio vs. $\boldsymbol{P}_{\text {ret }} / \boldsymbol{P}_{\text {unret }}$ data points. 
where the unit of $E_{F R P}$ is $\mathrm{MPa}$.

\section{Conclusions}

This study focused on evaluating the feasibility of using FRP retrofit technique to restore the flexural capacity of deteriorated bridge timber piles under eccentric loading. A total of 16 pile specimens were used in the study. Each specimen was tested before and after retrofitting with GFRP or CFRP sheets. To assess the impact of realistic field conditions, different details of the FRP retrofit technique were investigated including applying FRP with and without mortar shell, introducing mortar-filled wedge in the tested specimen prior to wrapping it with FRP to mimic the effect of severe damage, and posting the piles with nails instead of steel drift pins. The test results showed acceptable structural behavior for the specimens retrofitted with GFRP sheets, regardless of the retrofit details adopted in the tests. On average, specimens retrofitted with GFRPs showed strength $10 \%$ greater than that of unretrofitted specimens. The behavior of CFRP sheets however was less satisfactory due to the small thickness of the CFRP shell used as a result of the high strength of CFRP compared to GFRP. This resulted in excessive out of plane deformation of CFRP shell under large compressive stress. It was found from the study that using mortar shell along with FRP sheets helps in enhancing the stiffness of the retrofitted pile; hence is recommended for piles with higher levels of deterioration. The average mean and median reduction of stiffness of the retrofitted specimens was $5 \%$ and $14 \%$ of the unretrofitted specimens, respectively. Linear regression analysis was conducted on the test data, and a design value for the FRP volumetric ratio of $6.8 \%$ was determined for the GFRP type used in this study. This value was utilized along with the elastic design theory to propose a more generic formula for the design of retrofit for bridge timber piles using any FRP type.

\section{Acknowledgements}

The authors acknowledge the support for this study provided by the Illinois Center for Transportation (ICT) and the Illinois Department of Transportation (IDOT) under project No. R27-82.

\section{REFERENCES}

[1] IDOT, "Maximum Legal Dimensions \& Weights on State,
Federal \& Local Routes," Illinois Department of Transportation, Springfield, 2010.

[2] IDOT-SIMS, "IDOT Structures Information Management System," Accessed February 2012. http:/www.dot.state.il.us/sims/sims.html

[3] W. Walzer, "The Problem with Rural Bridges," Cooperative Extension Service, University of Illinois at UrbanaChampaign, Urbana, 1977.

[4] W. McCutcheon, R. Gutkowski and R. Moody, "Performance and Rehabilitation of Timber Bridges," Transportation Research Record 1053, 1986, pp. 65-79.

[5] T.J. Wipf, F. S. Fanous, F. W. Klaiber and A. S. Eapen, "Evaluation of Appropriate Maintenance, Repair and Rehabilitation Methods for Iowa Bridges," Final Report, Iowa DOT Project TR-429, 2003.

[6] D. J. Borello, B. Andrawes, J. F. Hajjar, S. M. Olson and J. Hansen, "Experimental and Analytical Investigation of Bridge Timber Piles under Eccentric Loads," Engineering Structures, Vol. 32, No. 8, 2010, pp. 2237-2246. doi:10.1016/j.engstruct.2010.03.026

[7] D. J. Borello, B. Andrawes, J. F. Hajjar, S. M. Olson, J. Hansen and J. Buenjer, "Forensic Collapse Investigation of a Concrete Bridge with Timber Piers," Research Report FHWA-ICT-09-042, Illinois Center for Transportation, Springfield, IL, 2009.

[8] M. Hagos, "Repair of Heavily Decayed Timber Piles Using Glass Fiber Reinforced Polymers (GFRP) and Cementitious Grout," M.Sc. Thesis, University of Manitoba, Winipeg, 2001.

[9] A. M. Pozolo, "Transfer and Development Lengths of Steel Strands in Full-Scale Prestressed Self-Consolidating Concrete Bridge Girders," M.S. Thesis, University of Illinois at Urbana-Champaign, Urbana, 2010.

[10] J. Ambrose and P. Tripeny, "Simplified Design of Wood Structures," 6th Edition, John Wiley \& Sons, Inc., Hoboken, 2009.

[11] A. H. Buchanan, "Combined Bending and Axial Loading in Lumber," Journal of Structural Engineering, Vol. 112, No. 12, 1986, pp. 2592-2609. doi:10.1061/(ASCE)0733-9445(1986)112:12(2592)

[12] F.C. Campbell, "Structural Composite Materials," ASM International, Materials Park, Ohio, 2010.

[13] American Forest \& Paper Association (AFPA), "National Design Specification (NDS) for Wood Construction," Washington DC, 2005. 